\title{
Application of the Artificial Neural Network Method to Estimate the Missing Hydrologic Data
}

\author{
Bin HE 1) Keiji TAKASE 2) \\ 1) United Graduate School of Agricultural Sciences, Ehime University \\ (Tarumi 3-5-7, Matsuyama-shi, 790-8566 Japan,) \\ ${ }^{2)}$ Faculty of Agriculture, Ehime University \\ (Tarumi 3-5-7, Matsuyama-shi, 790-8566 Japan,)
}

\begin{abstract}
The hydrologic conceptualization of virtual condition is relied on the behavior of monitored data at various monitoring gauges but there are frequently missing values in the monitoring database. Reasonably estimating these missing values is important for the complete analysis and modeling of hydrologic cycle. The linear regression and multivariable interpolation of monitored data were often used to estimate the missing data or check the inadequate data of the hydrologic database. But in many instances, the relationships between the predicting and predicted variables are not truly linear, and the non-linear forms of their relationships are very difficult to be known. In this paper the Artificial Neural Network (ANN) based model is employed using the pre-construction period data to evaluate the inadequate data and missing data in the hydrologic dataset without understanding the detail relation between input and output data elements. Prediction results present that ANN method with highest coefficient of determination $\left(\mathrm{R}^{2}\right)$ could be the desirable and preferred choice for evaluating the missing hydrologic data.
\end{abstract}

Key words: Artificial Neural Network; Multi-variable regression methods ; Missing hydrologic data

\section{I . INTRODUCTION}

Hydrology is important for its implications to flood prediction, pollution control and ecology management of watersheds and database is the most important for analyzing the properties of hydrology. Furthermore, suitable analysis by hydrologic numerical models and effective management of water resource systems require complete datasets. Thus for the understanding of hydrologic phenomenon, supplement of hydrologic record is also important by a complete observation of hydrologic database. However, a majority of dataset deficiency often occurs due to the presence of manual factors, malfunction of monitoring equipment, natural phenomena, etc. Thus it is necessary for researchers to check and complete the hydrologic datasets before starting their analysis. There are some traditional methods to complete the dataset such as linear regression, logarithmic, polynomial, power and exponential method, etc. But in many instances, the relationships between the predicting and predicted variables are not truly linear, and the non-linear forms of their relationships are very difficult to be known. In that case, a neural network modeling method which is a computational approach inspired by studies of the brain and nervous systems in biological organisms can be a welladapted alternative non-parametric solution to this problem. On the other hand, in order to design water resources systems that provide satisfactory performance in the future, the hydrologic characteristics of the time series should be taken into consideration. Also the 
discontinuous record of hydrologic database could either be short-term (few hours or few minutes) or long-term (few months even up to one year). Thus it is desirable to establish a simple and executable supplementary model for hydrologic record. In this paper the Artificial Neural Network (ANN), which is formulated using the pre-construction period data to evaluate the inadequate data and missing data in the hydrologic dataset, has been applied to overcome the problem of exclusive and the nonlinear relationships.

\section{II . METHODS}

\section{Artificial Neural Networks Method}

The ANN technique mimics the cognitive response of the human brain. And it is a flexible mathematical structure patterned after the biological functioning of the nervous system and considered to be a versatile tool for approximating complex functions that are difficult to model mathematically or evaluate numerically. Back propagation algorithm is a first-order gradient search method, which is capable of non-linear pattern recognition and memory association. Standard multi-layer feed forward networks are capable of approximating any measurable function to any desired degree of accuracy.

ANN is particularly useful for its simplicity, ability to capture the unknown non-linear relationships among variables and having less assumption in its applications (Gupta HK et al., 1995). The use of ANN modeling has been increasing in various aspects of science and engineering. It has also been used in many hydrologic problem such as forecasting reservoir inflow and river flow prediction [Coulibaly $\mathrm{P}$ et al., 2000; Karunanithi N et al., 1994], determining aquifer parameters [Aziz ARA et al., 1992], water quality parameters [Maier HR et al., 1996],etc. The ANN modeling can be seen as a sophisticated data oriented modeling technique to find relationship between input and output patterns without using detailed process knowledge. The ANN has the ability to represent non-linearity by means of a smaller number of parameters and least requirement of information regarding the process to be modeled.

\subsection{Artificial Neural Network Architecture}

So the ANN method can be quite useful in many practical hydrologic studies, as most of the hydrologic processes are complex and entail heavy empiricism. In this paper the ANN method will be applied to predict the missing or incomplete hydrologic data. The ANN configuration used here is organized in the form of layers.

In general, three-layers would be applied in ANN as an architecture example that is shown in the Fig.1. The first layer is the input layer consisting of neurons that receive an input from the external environment. It does not perform any transformations upon the input but just sends it to the processing elements of the neighbor's hidden layer. The last layer is the output layer consisting of neurons that receive the hidden layer output and send it to the user. The layer between the input and the output layer are so-called hidden layers consisting of neurons that typically receive the transferred data from the input layer, perform their transformation on it, and pass the data to the layer below it, which can be a second hidden layer or the output layer. A hidden layer of neurons may be defined as one without having direct connection paths to external inputs or outputs. Hidden layers add a degree of flexibility to the performance of

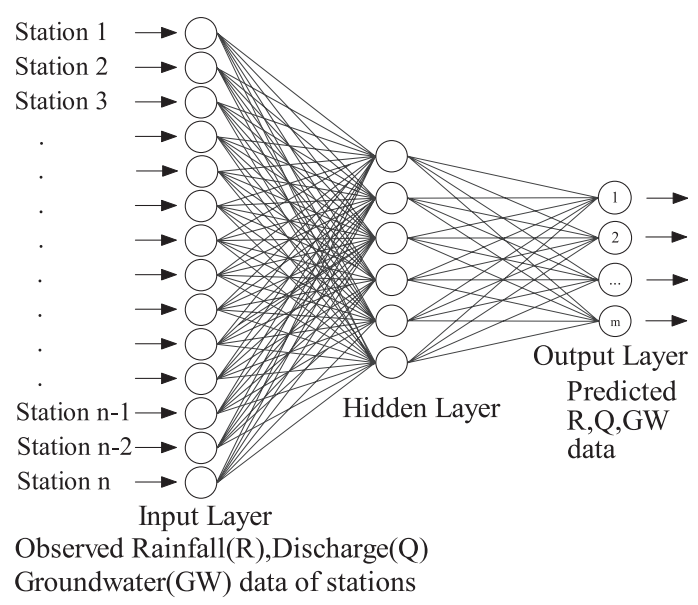

Fig. 1 ANN three-layer architecture used in this research. 
the neural network and to the internal representation of the problem under consideration that, in most cases, considerably enhances the capability of the network to deal robustly and efficiently with inherently complex nonlinear relations (Medsker LR, 1994). It can principally be chosen arbitrarily, but depends very much on the amount of data available of training and testing, as well as the non-linearity of the process that is to be modeled.

So a typical three-layer network with an input layer (I), hidden layer (H) and an output layer (O) (See Fig. 1) is adopted in this study. Each layer consists of several neurons and the layers are interconnected by sets of correlation weights. The dataset which were used for the identification of ANN model parameters were all known-value dataset. The dataset for verification of parameters were partially unknown according to the original database. The ranges of dataset that were used for the identification of ANN model parameters are very important for the verification of parameters. Thus the neurons receive inputs from the initial inputs or the interconnections and produce outputs by transformation using an adequate non-linear transfer function. The transfer function is the sigmoid function and the training process of neural network is essentially executed through a series of patterns. In the learning process, the interconnection weights are automatically adjusted within input and output value. Fig. 1 shows the concept of ANN three-layer architecture that is used in this research. The input layer is the known datum of gauging stations and the output layer is the unknown or predicted datum of gauging stations.

\subsection{Data Preparation and Standardization}

Three types of dataset that includes precipitation data, discharge data and groundwater data were prepared for the input layer in the ANN architecture. These are most representative datasets for hydrologists. A dataset of precipitation is a discontinuous one, which includes rainy and no-rainy days. A discharge dataset is a continuous one, which ranges widely, for example, from several $10^{-1}$ to several 10 or $10^{2} \mathrm{~mm} /$ day. A groundwater level dataset is also continuous and it ranges in several meters or centimeters.

For each dataset the missing data occurs in some period (several months or several weeks). But it is not all the data is missing in the same period of all gauges, so it is capable for us to use the available datum to predict the unknown data by ANN method.

In this study the sigmoid function was used to result in a better normalized mean squared error (NMSE) for all the randomized datasets. Due to the nature of the sigmoid function, it was necessary to standardize the data in a range between 0 and 1 . The ANN would require extremely small weighting factors causing computational inaccuracies due to floating point calculations, sluggish training and the near-zero gradient of sigmoid function at extreme values (Dawson CW and Wilby R, 1998). Therefore, in the present study, the input values were standardized with respect to the maximum and minimum values in the range, as this provided better model predictions than other approaches of standardization.

$$
\overline{X_{i}}=\left(X_{i}-X_{i \min }\right) /\left(X_{i \max }-X_{i \min }\right)
$$

Where $\overline{X_{i}}$ is the respective standardized value for the node; $X_{i}$ is the actual value of node i; $X_{i \min }$ and $X_{i \max }$ are the minimum and maximum of all values applied to the node respectively.

\subsection{Neural Networks Training and Evaluation}

ANN is trained with a set of known-value input and output data that is similar to the calibration of conceptual models. The training process was repeated with different sets of shuffled data. The NMSE was noted for each analysis and cross validation was done to estimate the $\mathrm{R}^{2}$ values. The learning process was terminated when an optimum prediction statistic was obtained in relation to epoch size and cross-validation results. In this study the sigmoid transfer function was used:

$$
f(x)=1 /\left(1+e^{-x}\right)
$$


The model efficiency factor (E), coefficient of determination $\left(\mathrm{R}^{2}\right)$ and absolute average deviation (AAD) between the observed and the predicted values were estimated for different prediction object such as rainfall, discharge and groundwater datasets. The efficiency factor was estimated for all the validation sets using the NMSE that is determined from:

$$
E=\sum_{n=1}^{N} \sum_{p=1}^{P}\left(D_{n p}-Z_{n p}\right)^{2} / \sum_{n=1}^{N} \sum_{p=1}^{P}\left(D_{n p}-\overline{D_{n p}}\right)^{2}
$$

Where $P=$ total number of input elements; $\mathrm{N}$ is the total number of output elements; $D_{n p}$ is the target outputs in transformed values; $Z_{n p}$ is the network's outputs in transformed values. The NMSE is the sum of squared errors normalized by the number of patterns over all output nodes and the estimated variance of the data. If subtracting the NMSE by unity, the result would be statistically similar to the $\mathrm{R}^{2}$ of the ANN model. Thus from the above statement once the training process was satisfactorily completed, the network was saved, the test and validation datasets were recalled and the model-predicted values were compared with observed values.

\section{Regression Method}

In order to verify or compare the efficiency of ANN method, regression methods were also applied to estimate the missing data. As one of the most popular regression methods, linear least squares regression (LLSR) has earned its place as the primary tool for process modeling because of its effectiveness and completeness and it is by far the most widely used modeling method. However, the main disadvantages of linear least squares regression method are limitations in the shapes that linear models can assume over long ranges, possibly poor extrapolation properties, and sensitivity to outliers. Though there are types of data that are better described by functions that are nonlinear in the parameters, many processes in science and engineering are well described by linear models. Linear least squares regression can be used to fit the data with the function of the following form.

$$
f(\bar{x} ; \bar{\beta})=\beta_{0}+\beta_{1} x_{1}+\beta_{2} x_{2}+\ldots
$$

where, each explanatory variable in the function is multiplied by an unknown parameter $\beta$. There is at most one unknown parameter with no corresponding explanatory variable, and all of the individual terms are summed to produce the final function value.

In statistical terms, any function that meets these criteria would be called a "linear function". The term "linear" is used, even though the function may not be a straight line, because if the unknown parameters are considered to be variables and the explanatory variables are considered to be known coefficients corresponding to those "variables", then the problem becomes a system (usually over-determined) of linear equations that can be solved for the values of the unknown parameters. So linear models are not limited to being straight lines or planes, but include a fairly wide range of shapes. For example, a simple quadratic curve:

$$
f(\bar{x} ; \bar{\beta})=\beta_{0}+\beta_{1} x+\beta_{2} x^{2}+\ldots
$$

is linear in the statistical sense.

A straight-line model in logarithm ,

$$
f(\bar{x} ; \bar{\beta})=\beta_{0}+\beta_{1} \log (x)
$$

is also linear in the statistical sense because they are linear in the parameters, though not with respect to the observed explanatory variable. And in this paper, as the representative of popular regression methods, multi-variable regression (MVR) method was used to predict the missing hydrologic data comparing with the ANN method.

\section{Example Database Description}

The experimental database for this study were collected in the Dogo Plain of Ehime Prefecture, which is located in the Shikoku Island and the neighboring mountainous area (As shown in Fig.2). The study site is situated at a longitude of 132.46 


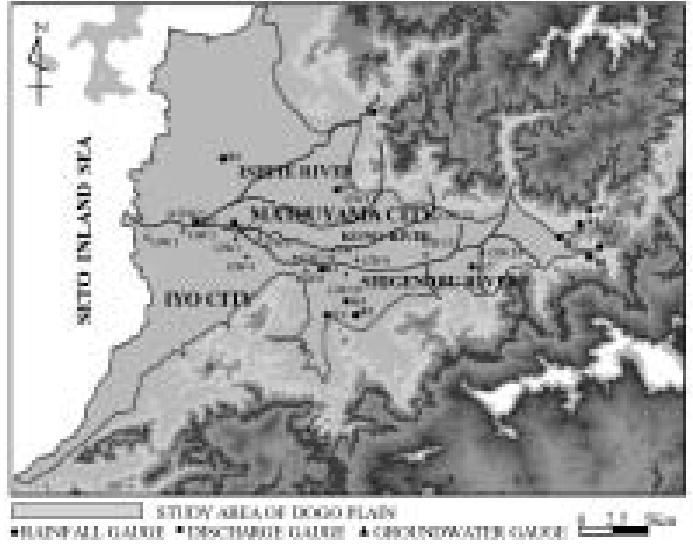

Fig. 2 Map of study site showing the location of the Dogo plain and the experimental gauges in it.

degrees east and 33.50 degrees north, 7 degrees further south than Tokyo. Dogo plain has a mild climate, characteristic of the Seto Inland Sea, with an average temperature of 16 degrees. The average annual precipitation is around $1,300 \mathrm{~mm}$, with a lot of rain in June and only a little in January. The study plain covers an area of $83 \mathrm{~km}^{2}$, terrain elevation ranges from 83-180 $\mathrm{m}$ above sea level.

The Dogo plain is one of the major plains in Ehime Prefecture of Japan. In view of preserving the area with its ecological considerations, the study and research of the Dogo plain has been continuously monitored for rainfall, stream flow, groundwater level, groundwater temperature and electrical conductivity for about 30 years. The continuously monitored data like these could be helpful in the detailed conceptualization of the hydro-geological environment and also the complete monitoring database is very important before hydrologic analysis.

\section{RESULTS AND DISCUSSION}

Based on the aforementioned procedure, the missing data of rainfall, discharge and groundwater can be predicted. As examples of the comparison between ANN and MVR methods, the different dataset of rainfall, discharge and groundwater measured in the study site has been chosen. The dataset has been chosen considering the number of missing data and the relation between different measurement gauges. In general, if the number of missing data is large but the relation between the object gauge and other gauges is clear in the same period (day or year), that gauge can be chosen as a typical prediction object using ANN and MVR methods. In all of these datasets the missing data has been found for three or four months in some years. The estimation results of each type of database will be analyzed in the following sections.

\section{1) Daily Rainfall Data}

For rainfall database, the daily rainfall value in 1997 has been collected as an example. There are five rainfall stations as input layer of ANN model. Measured dataset among five rainfall stations were used for the identification of ANN model parameters and the missing data were predicted by using the verification process of parameters. The results of forecast using the ANN model and MVR method with the same input dataset are presented in Fig. 3. In the Fig. 3, the trend line and correlation coefficient between the measured and predicted rainfall data value of both measured and predicted data using ANN, MVR method have been shown. It is clear for us to find that the ANN model can be applied to the missing rainfall data's forecasting problem and it seems to have reached encouraging results. And it can be also found that a very close fit can be obtained during the prediction process by

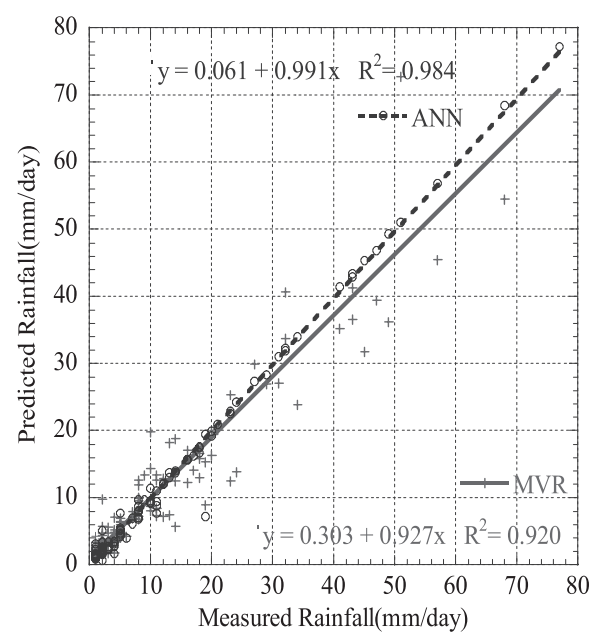

Fig. 3 Trend line and correlation coefficient between the measured and predicted rainfall data. 
ANN method and the result is better than those reached by the MVR method. The relative errors between measured value and predicted value are $20.34 \%$ and $49.74 \%$ for all rainfall data using the ANN and MVR method, respectively. The relative errors between measured value and predicted value are $6.91 \%$ and $25.77 \%$ for the rainfall data which was greater than $5 \mathrm{~mm} /$ day using the ANN and MVR method, respectively.

In some cases there is only one gauge in which the rainfall data is available. So the comparison was also conducted by employing the ANN model and MVR method. In such a case the MVR method is much better than the ANN model so that MVR method is simpler and preferred. And also the rainfall data is so discontinuous that the time series ANN method can't be easily employed to predict the missing rainfall data. Thus it is preferred to use MVR method if there are only one or two gauges in which the rainfall data is available.

\section{2) Daily Discharge Data}

For the discharge data, the daily discharge in year 1999 has been chosen as an example assessment object. There are seven discharge stations as input layer of ANN model. Measured dataset among seven discharge stations were used for the identification of ANN model parameters and the missing data were predicted by using the verification process of parameters. Scatter plots showing the observed (historical) discharge on the $x$-axis against the forecasted discharge from the
ANN and MVR methods on the $y$-axis are displayed in Fig. 4 for the test dataset. In the scatter plot a perfect forecast lies on the $45^{\circ}$ line in the ANN prediction. This illustrates that the ANN is accurate at forecasting the missing discharge values. The relative errors between measured value and predicted value are $26.53 \%$ and $40.04 \%$ for ANN and MVR, respectively. From Fig.5, it was found that there was a considerable range of errors in forecasting the missing discharge data based on the MVR method. The discharge value of both measured and predicted data using ANN and MVR method has been shown in different line type. The figures show that the ANN model performed well at forecasting both the magnitude and timing of the peak fluctuations. And also

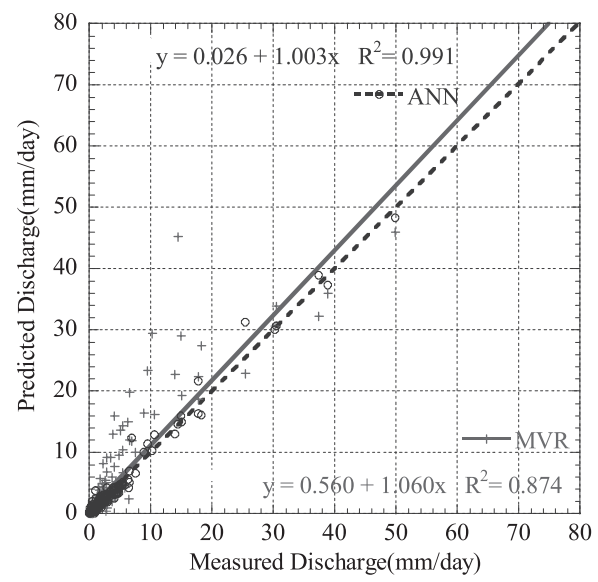

Fig. 4 Trend line and correlation coefficient between the measured and predicted discharge data.

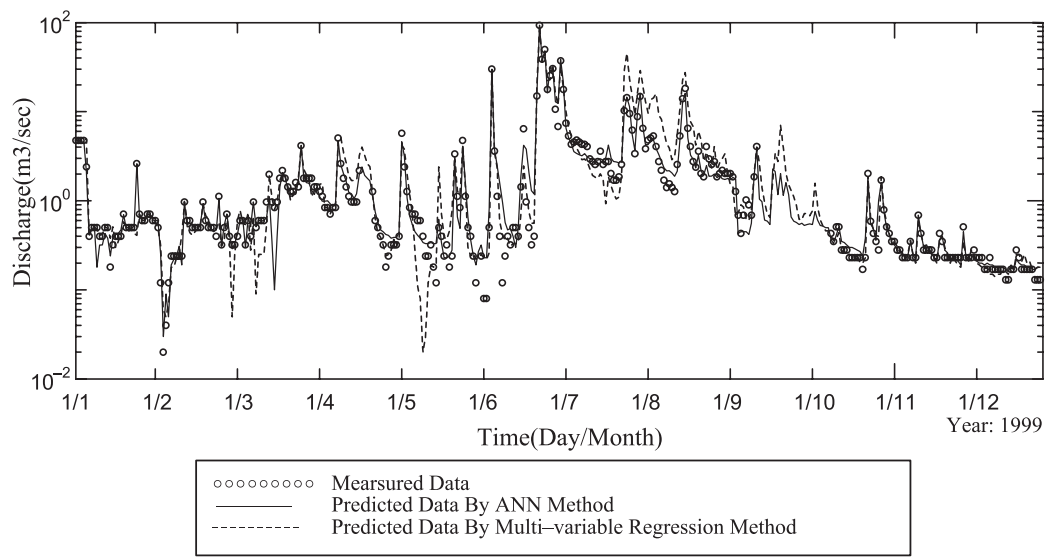

Fig. 5 Time series figures showing the comparison and difference between predicted and measured discharge. 
there is a considerable range of errors in forecasting the magnitude of the hydrologic data using MVR method, especially the large difference of peak fluctuation occurred in May and June of this year.

In some cases there is only one gauge in which the discharge data is available. So the comparison was also conducted by employing the ANN model and MVR method. In such a case the MVR method is also much better than the ANN model and MVR method is simpler and preferred. But for discharge database the time-series ANN method can be employed to predict the missing discharge data because the discharge data is continuous. The desirable prediction results can be obtained from the time series ANN model and its result is much better than MVR model. So in this case, the time series ANN model can be employed to estimate the missing discharge data.

\section{3) Daily Groundwater Elevation Data}

For groundwater data the daily groundwater elevation in year 1992 has been chosen as the example assessment object. There are thirteen groundwater stations as input layer of ANN model. Measured dataset among thirteen groundwater stations were used for the identification of ANN model parameters and the missing data were predicted by using the verification process of parameters. The results of forecasting using the ANN model and MVR method with the same inputs are presented in Fig. 6.

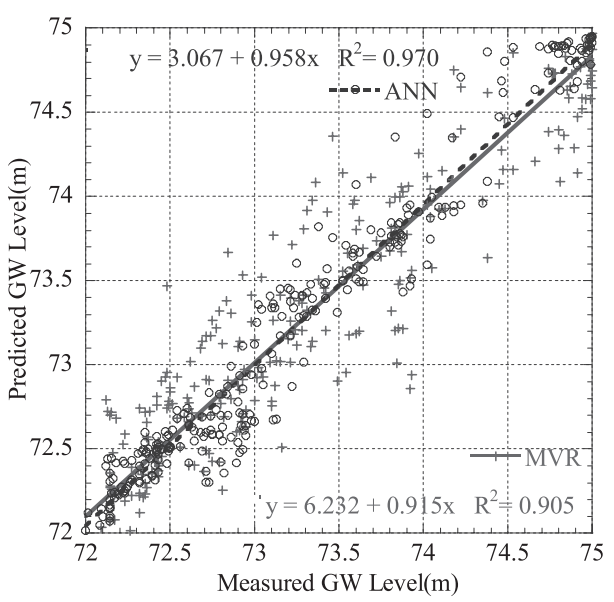

Fig. 6 Trend line and correlation coefficient between the measured and predicted groundwater data.

It also can be seen from Fig. 6 that the correlation coefficient over one year is 0.970 , which is reasonable value. This demonstrates the promising compatibility of the proposed ANN model in the learning and supplement of groundwater data. The prediction of the present model agrees well with the observation value. The relative errors between measured value and predicted value are $0.19 \%$ and $0.34 \%$ for ANN and MVR, respectively. The average absolute error between measured value and predicted value are $0.136 \mathrm{~m} / \mathrm{d}$ and $0.249 \mathrm{~m} / \mathrm{d}$ for ANN and MVR, respectively. Fig. 7 shows that the ANN model performed well at forecasting both the magnitude and timing of the peak fluctuations in the groundwater test dataset.

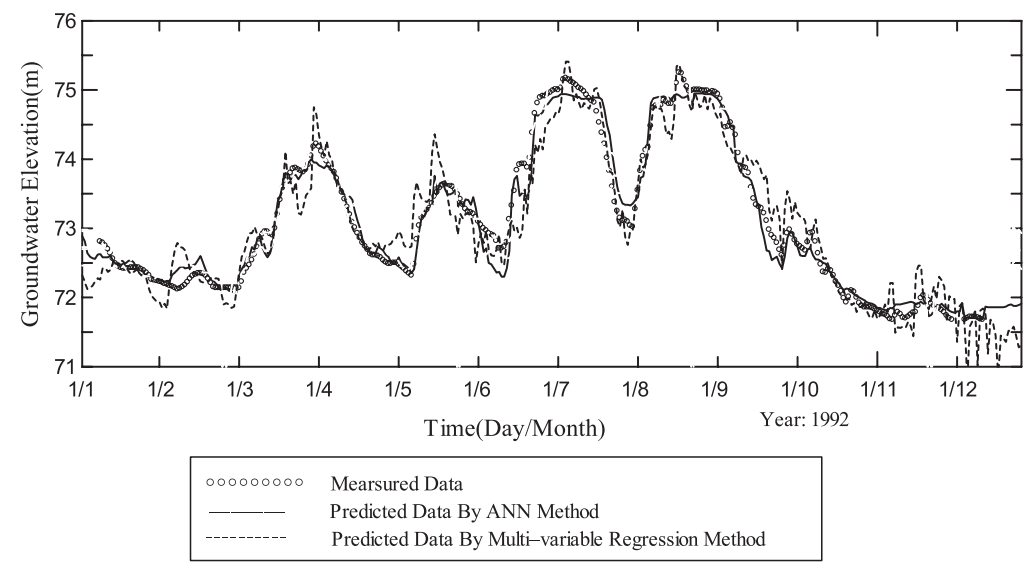

Fig. 7 Time series figures showing the comparison and difference between predicted and measured groundwater fluctuations. 
In some cases there is only one gauge in which the groundwater data is available. So the comparison was also conducted by employing the ANN model and MVR method. In such a case the MVR method is much better than the ANN model and MVR method is simpler and preferred. But for groundwater database the time-series ANN method can also be employed to predict the missing groundwater data because the groundwater data is continuous. The desirable prediction results can be obtained from the time series ANN model and its result is much better than MVR model. In this case, the time series ANN model can be employed to estimate the missing groundwater data. As can be seen from the Fig.7, in some cases there is even no measured data but the predicted value fit well with the trend of original groundwater data. The discontinuous observations may come from the damage of recording facilities, natural disasters or inappropriate operation and so on. From the above analysis, it can be seen that the artificial neural network is capable to estimate the missing hydrologic data with high accuracy.

\section{IV . CONCLUSION}

An ANN based prediction approach to estimate the missing hydrologic data is proposed in this paper. From the assessment in this paper, we can find that:

1. The trend line and correlation coefficient between the measured and predicted hydrologic data using ANN and MVR method has show that the ANN method is the prior choice to predict the missing data. The case study shows that the major constituents can be obtained and hydrologic missing data's forecast can be satisfactorily achieved from the observed data by ANN method. The proposed ANN method for predicting and supplementing the hydrologic dataset can be further applied to other locations or other types of dataset.
2. In some cases there are only one or two gauges in which the rainfall data is available. The comparison was also conducted by employing the ANN model and MVR method. In such a case the MVR method is much better than the ANN model and MVR method is simpler and preferred. But for discharge and groundwater database the time-series ANN method can be employed and the desirable prediction results can be obtained from it.

3. Linear regression models, for example, MVR method, is difficult to fit the data well as the range of the data value increases (for example, discharge data ranges from several $10^{-1}$ to several 10 or $10^{2} \mathrm{~mm} /$ day). This means that linear models may not be effective for extrapolating the results of a process for which data cannot be collected in the broad region of interest. It is critical to obtain sound answers to the questions by motivating the construction of ANN model.

4. The ANN's functions as a data-mining tool, in which the input and output dataset has to be fed to the software and trained before validating the model, have an advantage over deterministic models in that the dataset's requirements are usually less and they are well suited for longterm forecasting. The disadvantage of the ANN is that it is based on a 'black box' approach since the internal structure of the model is generally not known and must be developed by a trial and error process.

\section{ACKNOWLEDGEMENTS}

The authors wish to acknowledge the support and technical guidance given by the Laboratory of Hydrology for Environmental Science in Ehime University for undertaking this research. The research was financially supported by the Sasakawa Scientific Research Grant from The Japan Science Society. 


\section{REERENCES}

Aziz ARA, Wong KFV. 1992. A neural network approach to the determination of aquifer parameters. Groundwater 30 (2): 164-166.

Coulibaly P, Anctil F, Bobee B. 2000. A recurrent neural networks approach using indices of low-frequency climatic variability to forecast regional annual runoff. CGHU Special Issue of Hydrological Processes 14 (15): 2755-2777.

Dawson CW, Wilby R. 1998. An artificial neural network approach to rainfall-runoff modeling. Journal of Hydrological Science 43 (1): 47-66.

Govindaraju RS, Rao AR. 2000. Artificial Neural Networks in Hydrology. Kluwer Academic Publishers, Amsterdam.
Gupta HK, Sorooshian HV. 1995. Artificial neural network modeling of the rainfall-runoff process. Water Resources Research 31 (10): 2517-2530.

Karunanithi N, Grenney WJ, Whitley D, Bovee K. 1994. Neural networks for river flow prediction, Journal of Computer Technology in Civil Engineering ASCE 8 (2): 201-220.

Maier HR, Dandy GC. 1996. The use of artificial neural networks for the prediction of water quality parameters. Water Resources Research 32 (4): 1013-1022.

Medsker LR .1994. Hybrid Neural Network and Expert Systems. Kluwer Academic Publishers, USA.

(Received : Nov.22,2005, Accepted : Feb.8,2006)

\title{
人工神経回路モデルによる水文観測欠測データの補完
}

\author{
賀 斌 1） 高瀬恵次 2) \\ 1)愛媛大学大学院連合農学研究科 \\ (テ790-8566 愛媛県松山市樽味3-5-7) \\ 2)愛媛大学農学部 \\ ( ₹790-8566 愛媛県松山市樽味3-5-7)
}

水文現象を正しく理解するためには, 多くの観測データが必要であることはいうまでもない. しかし，それらの 観測では欠測の生ずることが多く，その久測值を精度よく補完することは水循環の解析やそのモデル化にとって重 要な課題である。このような補完あるいはデータのチェックには, これまで線形回帰式や重回帰式が用いられてき たが, 独立変数と従属変数の関係は線形でない場合も多く, その非線形関係を知ることは困難である. 本論文では, 人工神経回路モデル（ANN）を適用して，ブラックボックス的ではあるが久測水文データの補完を行ったそその結 果，予測值と実測值の間には非常に高い相関性が認められ，本方法は，水文デー夕の欠測補完に有用な手段である ことが示された。

キーワード：人工神経回路モデル，重回帰式，水文観測欠測データ 